\title{
Infectious Enterocolitis
}

National Cancer Institute

\section{Source}

National Cancer Institute. Infectious Enterocolitis. NCI Thesaurus. Code C80513.

An infectious process affecting the small and large intestines. Symptoms include diarrhea, cramping abdominal pain, and fever. 